\title{
Study on Knowledge and Practices of Water, Sanitation and Hygiene among Secondary School Students
}

\author{
Marina Vaidya Shrestha, ${ }^{1}$ Naresh Manandhar, ${ }^{1}$ Sunil Kumar Joshi ${ }^{1}$ \\ ${ }^{1}$ Department of Community Medicine, Kathmandu Medical College, Kathmandu, Nepal.
}

\begin{abstract}
Background: Provision of adequate water supply, sanitation, hygiene and waste management in schools has a number of positive effects. The study focuses on children because disease related to water; sanitation and hygiene are the leading cause of mortality and morbidity among children. Materials and Methods: This cross-sectional study comprised of 220 students. Participants involved were Government school students of grades 9-10 in Sindhupalchowk and Bhaktapur. Data consisted of hygiene and hand washing practices, knowledge about sanitation and personal hygiene characteristics. Results: This study revealed that knowledge regarding water borne disease was high among Urban school students $86.5 \%$ but knowledge regarding transmission route seemed inadequate in both urban and rural students $(35 \%$ and $16 \%$ respectively). The practice on hand washing was found high (94.4\%). There was significant difference in the knowledge of students regarding WASH in urban and rural settings of the school ( $\mathrm{P}$ value $<0.001)$. Treated water facility and hand washing facilities with water was found lacking in rural schools. Schools from the urban area had proper hand washing facilities, but there was not any soap available in both the areas. Conclusions: The knowledge and practice of Water, Sanitation and Hygiene (WASH) among secondary school students is still poor. The knowledge of WASH in secondary school students when compared to the rural areas, urban areas had better on the basis of knowledge score.
\end{abstract}

Keywords: hygiene; knowledge; practice; water; sanitation.

\section{INTRODUCTION}

"Knowledge, Attitude and Practices (KAP) survey is a quantitative method that provides access to quantitative and qualitative information and reveals misconceptions or misunderstandings that may represent obstacles to the activities to be implemented and potential barriers to behavior change". ${ }^{1}$ Poor hygiene practices and inadequate sanitary conditions play major roles in the increased burden of communicable diseases within developing countries. ${ }^{2}$ Provision of adequate water supply, sanitation; hygiene and waste management in schools have a number of positive effects. Children who have access to adequate water, sanitation and hygiene (WASH) conditions at school are more able to integrate hygiene education into their daily lives, and can be effective messengers and agents for change in their families and community. ${ }^{3}$ Good hygiene, sanitation and water-handling practices among students should be encouraged to transfer hygiene knowledge to their families and communities.

Nepal has proposed sustainable development goals
(SDG) targets for the year 2030 which includes achieving universal and equitable access to safe and affordable drinking water, sanitation and Hygiene for all. ${ }^{5}$ National water supply coverage of Nepal is $83.59 \%$ and sanitation coverage is $70.28 \%$ of the total population. ${ }^{6}$ 'Improved public health and living standard of people of Nepal through safe, sufficient, accessible, acceptable, and affordable water, sanitation and hygiene services- any time, everyone and everywhere' is the major development goal of the Government of Nepal and hence has shown commitment towards achieving basic water and sanitation for all by 2017 . $^{7}$

The study focuses on WASH; inadequate and poor WASH is the leading cause of mortality and morbidity among children. The objective of this study is to assess the school going children's knowledge and their practice on water, sanitation and hygiene in rural and urban area.

\section{MATERIALS AND METHODS}

A comparative descriptive cross-sectional study was

Correspondence: Dr. Marina Vaidya Shrestha, Department of Community Medicine, Kathmandu Medical College, Kathmandu, Nepal. Email: merinavs@gmail.com. Phone: +977-9851095640. DOI: 10.3126/jcmsn.v14i3.21158. Article received: 2018-06-29. Article accepted: 2018-09-20. 
conducted in rural and urban schools of Sindhupalchowk and Bhaktapur in January-February 2018. The study protocol and all amendments were reviewed and approved by the Institutional Review Committee of Kathmandu Medical College. The calculated sample size was 216 , taking prevalence of $52 \%{ }^{8}$ with confidence interval of $95 \%$ and margin of error of 0.07 . Convenient sampling method was applied. Students of grade 9 and 10 were involved from both urban and rural settings. Two schools were selected randomly from each of the two districts- Sindhupalchowk and Bhaktapur. The tools for data collection were: questionnaires, personal observation and a checklist. Orientation was given to all respondents regarding how to fill the questionnaire. Self-administered questionnaire was used for each respondent and was asked to fill the questionnaire individually without consulting their friend. Data were entered in SPSS version 20 and analyzed. Statistical test, mean and percentages were calculated.

\section{RESULTS}

The study was conducted among 220 students (grades 9 to 10) from Government school of Sindhupalchowk and Bhaktapur districts. Among the study students, $42.7 \%$ of the respondents were from rural schools and $57.2 \%$ from urban schools. In terms of gender, $48.2 \%$ of the respondents were male while $51.8 \%$ of the respondents were female. Comparing the knowledge among the Urban and the Rural students, $86.5 \%$ of students in urban area knew about the water borne disease in comparison to rural area $(74.5 \%)$ and about route of transmission $34.9 \%$ of the urban students expressed that contaminated water is the main source of water borne disease whereas only $16 \%$ of rural students knew about it. $94 \%$ of the urban students have knowledge that Diarrhea is water borne disease but it was less in rural students $(63.8 \%)$ and they got this knowledge from school.

Regarding quality of water, $66.6 \%$ urban students accepted that it effects health which is quite similar in context to rural setting(63.8\%). $74.6 \%$ students in urban areas have knowledge that unsafe drinking water may cause diarrhea whereas only $29.8 \%$ students in rural areas knew about this. To the knowledge of rural school students, $36.2 \%$ of their family members and $27.7 \%$ of their friends had suffered due to consumption of unsafe drinking water which was higher in comparison to urban area. It was seen that $92.6 \%$ of rural students had knowledge of prevention of water which was higher comparing to urban students' knowledge. Both urban and rural students had good knowledge that boiling kills germs (96\%). 97.9\% of rural students reported that water container needs cleaning and covering which was found higher than urban students knowledge. The majority of participants (84\%) reported the importance of hand washing after defecation in rural school which was found higher than the knowledge of the urban students, but there was no knowledge of critical hand washing in rural school students (Table 1).

\begin{tabular}{|c|c|c|c|c|}
\hline \multirow{2}{*}{$\begin{array}{l}\text { Statement } \\
\text { Knowledge of the students on }\end{array}$} & \multicolumn{2}{|c|}{$\operatorname{Urban}(\mathrm{n}=126)$} & \multicolumn{2}{|c|}{$\operatorname{Rural}(\mathrm{n}=94)$} \\
\hline & No. & $\%$ & No. & $\%$ \\
\hline Water borne disease & 109 & 86.5 & 70 & 74.5 \\
\hline $\begin{array}{l}\text { Route of transmission of water } \\
\text { borne disease }\end{array}$ & 44 & 34.9 & 15 & 16 \\
\hline - Through contaminated water & 32 & 25.3 & 5 & 5.3 \\
\hline Diarrhea is water borne disease & 94 & 74.6 & 60 & 63.8 \\
\hline $\begin{array}{l}\text { Water borne disease got from } \\
\text { school }\end{array}$ & 111 & 88 & 54 & 57.4 \\
\hline Quality of water effects health & 84 & 66.6 & 60 & 63.8 \\
\hline $\begin{array}{l}\text { Effects of unsafe drinking water } \\
\text { on human health is } \\
\text { - Diarrhoea }\end{array}$ & 94 & 74.6 & 28 & 29.8 \\
\hline $\begin{array}{l}\text { Suffering due to unsafe } \\
\text { drinking water among } \\
\text { - Family members } \\
\text { - Friends }\end{array}$ & $\begin{array}{l}39 \\
30\end{array}$ & $\begin{array}{l}30.9 \\
23.8\end{array}$ & $\begin{array}{l}34 \\
26\end{array}$ & $\begin{array}{l}36.2 \\
27.7\end{array}$ \\
\hline $\begin{array}{l}\text { Prevention of water borne dis- } \\
\text { ease }\end{array}$ & 114 & 90.4 & 87 & 92.6 \\
\hline Boiling kills germs & 120 & 95.2 & 90 & 95.7 \\
\hline $\begin{array}{l}\text { Water container needs cleaning } \\
\text { and covering }\end{array}$ & 118 & 93.6 & 92 & 97.9 \\
\hline Human faeces contain germs & 89 & 70.6 & 87 & 92.6 \\
\hline $\begin{array}{l}\text { Importance of handwashing } \\
\text { - after defecation } \\
\text { - during all critical handwash- } \\
\text { ing } \\
\text { - before meals }\end{array}$ & $\begin{array}{l}47 \\
45 \\
28\end{array}$ & $\begin{array}{l}37.3 \\
35.7 \\
22.2\end{array}$ & $\begin{array}{c}79 \\
0 \\
11\end{array}$ & $\begin{array}{c}84 \\
0 \\
11.7\end{array}$ \\
\hline $\begin{array}{l}\text { Reasons of handwashing } \\
\text { - Health } \\
\text { - Hygiene }\end{array}$ & $\begin{array}{l}87 \\
31\end{array}$ & $\begin{array}{c}69 \\
24.6\end{array}$ & $\begin{array}{c}87 \\
3\end{array}$ & $\begin{array}{c}92.6 \\
3.2\end{array}$ \\
\hline
\end{tabular}

There was significant difference between the knowledge of students in urban and rural settings of the school ( $\mathrm{p}$ value $<0.001)$ (Table 2).

\begin{tabular}{|llclll|}
\hline \multicolumn{5}{|l|}{ Table 2. Knowledge Score of the Students } \\
\hline Knowledge & Location & Total & p value \\
& Urban & Rural & & \\
Poor & 29 & 47 & 76 & \\
Good & 96 & 47 & 143 & $<0.001$ \\
Total & 125 & 94 & 219 & \\
\hline
\end{tabular}

Regarding the practices of the students on water, sanitation and hygiene (WASH), among urban school students $57.9 \%$ stored their drinking water in narrow closed container which was quite similar in rural setting. $62.8 \%$ of the rural students used to clean water storing container every day, 
$34 \%$ cleaned it before fetching water which was seen higher than urban setting. The practice of chlorination of water was seen higher $(38.3 \%)$ among rural students to make water safe. Among those who do not practice any of the water treatment methods in rural areas, $19.1 \%$ reported that water they used was already clean and safe and $5.3 \%$ added that treated water did not taste good which was less in comparison to urban students. $94.4 \%$ of students in urban areas practiced hand washing with soap and water which was comparatively higher to rural. Only few students in rural areas $(9.6 \%)$ practice hand washing with water only and $(1.1 \%)$ with ash which was comparatively higher than in urban areas. $98.9 \%$ of the students in rural areas prefer hand washing before meals which was comparatively higher than in urban students. 52.3\% urban students followed critical hand washing practices while $33 \%$ rural

\begin{tabular}{|c|c|c|c|c|}
\hline Statement & & an & & ral \\
\hline Practices of the students on & No. & $\%$ & No. & $\%$ \\
\hline $\begin{array}{l}\text { Drinking water storage container } \\
\text { - Narrow mouth closed }\end{array}$ & 73 & 57.9 & 53 & 56.4 \\
\hline $\begin{array}{l}\text { Cleaning water storing container } \\
\text { Everyday } \\
-\quad \text { Before fetching water }\end{array}$ & $\begin{array}{l}66 \\
36\end{array}$ & $\begin{array}{l}52.3 \\
28.5\end{array}$ & $\begin{array}{l}59 \\
32\end{array}$ & $\begin{array}{l}62.8 \\
34\end{array}$ \\
\hline $\begin{array}{l}\text { Method use to make water safe } \\
\text { - Boil } \\
\text { - } \quad \text { Strain through cloth } \\
\text { - } \quad \text { chlorine }\end{array}$ & $\begin{array}{l}91 \\
24 \\
9\end{array}$ & $\begin{array}{l}72.2 \\
19 \\
7.1\end{array}$ & $\begin{array}{l}15 \\
25 \\
36\end{array}$ & $\begin{array}{l}16 \\
26.6 \\
38.3\end{array}$ \\
\hline Consume boil water & 95 & 75.3 & 17 & 18.1 \\
\hline $\begin{array}{l}\text { Reason for not practicing any } \\
\text { methods of treatment } \\
\text { - water is already clean and } \\
\text { safe } \\
\text { - treated water do not taste } \\
\text { good }\end{array}$ & $\begin{array}{l}8 \\
1\end{array}$ & $\begin{array}{l}6.3 \\
0.7\end{array}$ & $\begin{array}{l}18 \\
5\end{array}$ & $\begin{array}{l}19.1 \\
5.3\end{array}$ \\
\hline $\begin{array}{l}\text { Materials use for handwashing } \\
\text { - soap and water } \\
\text { - } \text { water only } \\
\text { - Ash }\end{array}$ & $\begin{array}{l}119 \\
6 \\
1\end{array}$ & $\begin{array}{l}94.4 \\
4.7 \\
0.7\end{array}$ & $\begin{array}{l}84 \\
9 \\
1\end{array}$ & $\begin{array}{l}89.4 \\
9.6 \\
1.1\end{array}$ \\
\hline Handwashing before meals & 122 & 96.8 & 93 & 98.9 \\
\hline $\begin{array}{l}\text { Handwashing } \\
\text { - In all critical handwashing } \\
\text { - After defecation }\end{array}$ & $\begin{array}{l}66 \\
31\end{array}$ & $\begin{array}{l}52.3 \\
24.6\end{array}$ & $\begin{array}{l}38 \\
31\end{array}$ & $\begin{array}{l}40.4 \\
33\end{array}$ \\
\hline
\end{tabular}

students prefer hand washing practice only after defecation (Table 3 ).

The situations of sanitation facilities among 4 schools (2 from urban and 2 from rural) under study were analyzed. In this study the observation checklist showed that both of the schools in urban region used ground water supply whereas the schools in rural regions used surface water supply and ground water supply. One of the schools in urban region had underground tank and while other had underground and roof top tank. In case of rural region one of the schools had reserve plastic tank and other had underground tank. Only schools in urban region provided treated water to their students while rural schools did not have such facility. The study showed that only urban schools had hand washing facilities with water. The present study showed that all schools had coverage of improved toilets. Schools in urban region had adequate toilets while toilets in rural regions were not adequate to students. Regarding the distance of the toilet, both schools in urban region had easy access to the toilet

\begin{tabular}{|c|c|c|}
\hline Checklist & Urban(2) & Rural (2) \\
\hline Availability of water supply source & No. & No. \\
\hline Available ground water & 2 & 1 \\
\hline Available surface water & - & 1 \\
\hline \multicolumn{3}{|l|}{ Availability of water storage } \\
\hline Underground tank & 1 & 1 \\
\hline Underground and top tank & 1 & - \\
\hline Reserve plastic tank & & 1 \\
\hline \multicolumn{3}{|l|}{ Availability of treated water } \\
\hline Available & 2 & - \\
\hline Not available & - & 2 \\
\hline \multicolumn{3}{|l|}{ Availability of handwashing facility } \\
\hline Available & 2 & - \\
\hline Not available & - & 2 \\
\hline \multicolumn{3}{|l|}{$\begin{array}{l}\text { Availability of water at handwashing } \\
\text { facility }\end{array}$} \\
\hline Available & 2 & - \\
\hline Not available & - & 2 \\
\hline \multicolumn{3}{|l|}{$\begin{array}{l}\text { Availability of soap at handwashing } \\
\text { facility }\end{array}$} \\
\hline Available & - & - \\
\hline Not available & 2 & 2 \\
\hline \multicolumn{3}{|l|}{ Availability of sufficient toilets } \\
\hline Available & 2 & - \\
\hline Not available & - & 2 \\
\hline \multicolumn{3}{|l|}{ Accessibility of toilets } \\
\hline Accessible & 2 & 1 \\
\hline Not accessible & - & 1 \\
\hline \multicolumn{3}{|l|}{ Availability of improved toilets } \\
\hline Available & 2 & 2 \\
\hline Not available & - & - \\
\hline
\end{tabular}

while one of the schools in rural region had poor access (Table 4).

\section{DISCUSSION}

In this study 9-10 grade students were enrolled to know their knowledge and practices in water, sanitation and hygiene (WASH). The respondents were from the Government schools, so we did not intend to take lower grade students. This study was a comparative study among Urban and Rural school. The study in Vhembe ${ }^{10}$ was quite similar to this study in many contexts while in other studies only the primary school children were enrolled in urban settings. ${ }^{8,9,11,12,13}$ In this study regarding water borne disease, $86.5 \%$ of urban students had knowledge and similar result was found in study of Vhembe $^{10}$ that knowledge among urban students was higher than rural. This study revealed only $25.3 \%$ of urban students had knowledge of 
contaminated water as the main source of water borne disease and they got this information from school. The results were similar to Vhembe ${ }^{10}$ and Vivas et al., ${ }^{8}$ in the context that $60 \%$ of the students did not know the disease transmission routes. In this study, $74.6 \%$ of the urban students knew diarrhea as a water borne disease whereas in Vhembe, ${ }^{10} 76.80 \pm 1.75 \%$ of the respondents knew about waterborne diseases, even though they could not differentiate between cholera and diarrhea. The study showed suffering due to water borne disease among family members and friends of rural students were $36.2 \%$ and $27.7 \%$ respectively which was bit higher in comparison to urban students but was in contrast with study in Vhembe ${ }^{10}$ where majority of the respondents did not know anyone who had been affected by a waterborne disease. $92.6 \%$ of rural students in this study knew about prevention of water borne disease which was higher in comparison to urban setting while comparing with study in Vhembe, majority of the respondents had no knowledge.

In one of the question whether boiling kills germs, $95 \%$ students in both settings accepted it, which was in contrast to the findings in Vivas et al., ${ }^{8}$ where it was $61.4 \%$.In this study, $98 \%$ of rural students had knowledge that water container needs cleaning and covering. This result was quite higher comparing to urban schools in our own context. The reason can be stated as students in rural setting (mostly girls) had to go to fetch water and practically involve in household activities, so they had better knowledge regarding this. This finding was quite similar to study in Vivas et al $(94.3 \%){ }^{8}$ In this study $92.6 \%$ of the students had knowledge that human faeces contains germs which was similar to the study Vivas et al., ${ }^{8}$ but was less in Shilunga et $\mathrm{al}^{11}(62.9 \%)$; Knowledge on importance of hand washing after defecation, during critical hand washing and before meals in this study was similar to the study of Dajaan ${ }^{15}$ and was different in comparison to Vivas et al. ${ }^{8}$

The knowledge score in this study was used to compare among location (rural and urban setting) of the school and knowledge of the students. Similar scoring was done in another study Sarkar $\mathrm{M}^{9}$ and Shilunga et al., ${ }^{11}$ but it was used to show the association of knowledge with gender and ethnicity and learner's age and school grade respectively.

Regarding the practices of the students on WASH, in our context, around equal number of students in rural and urban settings (56\%) used narrow container for water storage which was cleaned everyday. This was different in context of western Kenya ${ }^{13}$ where $86 \%$ used Clay pots for household water storage with lid covers and had not mentioned about the cleaning practices of those storage containers. In this study different methods were used for water treatment. Boiling was the commonest method used among students in urban(72.2\%) while chemical method chlorine among rural (38.3\%)and $26 \%$ straining through cloth which was similar to the study of kenya ${ }^{13}$ where as $42 \%$ boiling, around $20 \%$ straining, $35 \%$ chemical (water guard was used). The study of Vivas et al., ${ }^{8}$ showed only boiling as method of water treatment. In this study the respondents who did not use any of the treatment methods were asked the reason for not using, 19.1\% students in rural schools replied that water was clean and safe to drink; only $5.3 \%$ said that treated water did not taste good. This was the cultural and social aspect of the rural students which was different from the study of Kenya where the study focused on water guard only, where $57 \%$ expressed it as expensive and $17 \%$ said that water is safe to drink.

Regarding the practice of hand washing in this study, $94.4 \%$ used soap and water which was similar to the study of Dajaan ${ }^{14}$ and comparatively the practices were less in the study of Vivas et al., ${ }^{8}$ Kenya $^{13}$ and Behera. ${ }^{12}$ Besides soap water, hand washing practices by water only, was common in study of Vhembe ${ }^{10}$ and Vivas ${ }^{8}$ and less common in study of Behera ${ }^{12}$ and Dajaan. ${ }^{14}$ Hand washing practice before meal was higher in this study which was similar to most of the studies been referenced for this study except Vhembe ${ }^{10}(65 \%)$ and Sarkar ${ }^{9}$ $(75.9 \%)$. Critical hand washing was preferred as the best washing practices but it was not high in this study as well as in other studies.

The source of water in the schools in this study was ground and surface water which was different in other studies: Municipal supply and borehole water in Vhembe. ${ }^{10}$ Water source had not been mentioned in study of Kenya. ${ }^{13}$ Private vendors in Giardina ${ }^{15}$ and $17 \%$ piped water by the local water authority in Gisore. ${ }^{16}$ Rain water harvesting in Elobeid. ${ }^{17}$ In the study $50 \%$ of school had underground tank and rest $25 \%$ had underground and top tank and reserve tank which was similar to study of Vhembe ${ }^{10}$, Elobeid ${ }^{17}$ and Gisore. ${ }^{16}$ Only $50 \%$ of the school used treated water in this study whereas in only 2 studies Kenya $^{13}$ and Giardina ${ }^{15}$ water treatment was done by chemical method. In the study of Gisore ${ }^{16}$ and Elobeid, ${ }^{17}$ no treated water was supplied. Only $50 \%$ 
coverage of hand washing facility was shown in this study which was similar to study in Gisore ${ }^{16}$ in contrary to the study in Vhembe which had $100 \%$ coverage. There was no hand washing facilities in all schools surveyed in Eleboid and Giardina. Only $50 \%$ of the schools had water in hand washing facility which was similar to study in Gisore whereas no water available in study of Giardina. In the study of Kenya, all the schools had water supply in hand washing facility. In this study no soap was provided at the hand washing facility. This result was consistent with studies conducted in Vhembe and Elobeid. The findings were different in Kenya and in Giardina with availability of soap. All the schools in this study were improved type with 50\% sufficient rate(inadequacy of latrines) which was similar with the study in Elobeid and Gisore whereas the study in Vhembe

\section{REFERENCES}

1. USAID. The KAP survey model (knowledge, attitudes, \& practices) 2011. [Cited on 2017.Nov. $\left.27^{\text {th }} 11.02 .43 \mathrm{am}\right]$. Available from (https:// www.springnutrition.org/sites/default/files publicationsannotationspring kap survey model.pdf.

2. Murray CJL, Lopez AD. The Global Burden of Disease: A Comprehensive Assessment of Mortality and Disability from Diseases, Injuries, and Risk Factors in 1990 and Projected to 2020. Cambridge:HarvardUniversityPress;1996.(http:// apps.who.int/iris/bitstream/ handle/10665/41864/0965546608_eng.pdf? sequence $=1 \&$ is Allowed $=\mathrm{y}$ ).

3. Adams J, Bartram J, Chartier Y, Sims J.Water, sanitation and hygiene standards for schools in lowcostsettings.WorldHealthOrganization.2009.(http:// www.who.int/water_sanitation_health/publications/ wash_standards_school.pdf).

4. UNICEF.WASH in schools monitoring package. April 2011.(https://www.unicef.org/wash/schools/ files/wash_in_schools_monitoringpackage_pdf)

5. National Planning Commission, 2017: Nepal's Sustainable Development Goals, Baseline Report, 2017. Government of Nepal, National Planning Commission, Kathmandu, Nepal.(https:// www.npc.gov.np/images/category/

SDGs_Baseline_Report_final_29_June-1(1).pdf).

6. Government of Nepal, Ministry of Urban development. Department of water supply and sewerage. Nation wise coverage and functionality status of water supply and sanitation of Nepal. National Management and information project Oct 2014.

7. Government of Nepal, Ministry of water supply and sanitation sector efficiency improvement unit (SEIU).Nepal Water Supply, Sanitation and Hygiene Sector Development Plan (2016-2030) Draft 2016.(www.seiu.gov.np/index.php/documents/ download-file?path=SDP\%2B-\%2BFinal). and Kenya showed adequacy of latrines in school.

\section{CONCLUSIONS}

The knowledge and practice of Water, Sanitation and Hygiene (WASH) in secondary school students is still poor. The knowledge ofWASH in secondary school students is better in urban areas as compare to the rural areas on the basis of knowledge score. The practices of Water, Sanitation and Hygiene (WASH) at those schools are critically poor.

\section{ACKNOWLEDGEMENTS}

Authors would like to thank all the schools who gave permission for this study and the participants for their valuable information.

\section{Conflict of Interest: None}

8. Vivas A, Gelaye B, Aboset N, Kumie A, Berhane Y, Williams MA. Knowledge, Attitudes, and Practices (KAP) of Hygiene among School Children in Angolela, Ethiopia. J Prev Med Hyg. 2010;51(2): $73-$ 9.(https://www.ncbi.nlm.nih.gov/pubmed/21155409.

9. Sarkar M. Personal hygiene among primary school children living in a slum of Kolkata, India. Journal of Preventive Medicine and Hygiene. 2013;54(3):153-8. (https://www.ncbi.nlm.nih.gov/pmc/articles/ PMC4718376/).

10. Jerry E. Sibiya and Jabulani Ray Gumbo. Knowledge, Attitude and Practices (KAP) Survey on Water, Sanitation and Hygiene in Selected Schools in Vhembe District, Limpopo, South Africa. Int. J. Environ. Res. Public Health 2013, 10, 2282-2295; doi:10.3390/ijerph10062282.(https://

www.ncbi.nlm.nih.gov/pubmed/23736657).

11. Shilunga A P K, Amukugo J.H , Mitonga K H. Knowledge, attitudes and practices of primary schools learners on sanitation and hygiene practices.Int J Community Med Public Health. 2018 Aug;5(8):3197-3204. DOI: http:// dx.doi.org/10.18203/2394-6040.ijcmph20183051 (https://www.researchgate.net/

publication/326569705_Knowledge_attitudes_and_pr actices_of_primary_schools_learners_on_sanitation_ and_hygiene_practices/download).

12. Behera B K, Jena S K, Shakthipriya A M, Behera A A,Samal S. Hygiene practices among rural school children in Puducherry.Journal of Evolution of Medical and Dental Sciences 2013; Vol2, Issue 24, June 17; Page: 4363-4372.(https:// www.researchgate.net/ publication/307691339_HYGIENE_PRACTICES_A MONG_RURAL_SCHOOL_CHILDREN_IN_PUD UCHERRY).

13. O'Reilly CE. The impact of a school-based safe water and hygiene programme on knowledge and practices of students and their parents:Nyanza Province, western Kenya, 2006.Epidemiol. Infect. (2008), 136, 


\section{Shrestha et al. Study on Knowledge and Practices of Water, Sanitation and Hygiene among..}

80-91. f 2007 Cambridge University Press doi:10.1017/S0950268807008060.(https:// www.ncbi.nlm.nih.gov/pubmed/17306051.

14. Dajaanetal. Hand washing knowledge and practices among public primary schools in the Kintampo Municipality of Ghana.Int J Community Med Public Health. $2018 \quad$ Jun;5(6):2205-2216(http:// www.ijcmph.com/index.php/ijcmph/article/ view/2964).

15. Giardina D, Prandini F, Sorlini S. Integrated Assessment of the Water, Sanitation and Hygiene Situation in Haitian Schools in the Time of Emergency.Sustainability 2013， 5, 3702-3721; doi:10.3390/su5093702.(https://www.mdpi.com/2071 $-1050 / 5 / 9 / 3702)$.
16. Gisore A W. An assessment of sanitation facilities in public primary schools in Kajiado central district. A Dissertation Submitted in Partial Fulfillment for the Award of the Degree of Master of Public Health (MPH) of the University of Nairobi.22 0ctober 2013. (http://erepository.uonbi.ac.ke/bitstream/ handle/11295/60015/Gisore_An\%20assessment $\%$ 20of $\% 20$ sanitation $\% 20$ facilities $\% 20$ in $\% 20$ public $\%$ 20primary $\% 20$ schools.pdf? sequence $=3$ ).

17. Ismail M. Assessment of water, sanitation and hygiene among basic schools in Elobeid. European journal of pharmaceutical and Medical research.ejpmr, 2017,4(5), 38-44.(http:// www.ejpmr.com/admin/assets/ article issue/1493372943.pdf).

Citation: Shrestha MV, Manandhar N, Joshi SK. Study on Knowledge and Practices of Water, Sanitation and Hygiene among Secondary School Students. JCMS Nepal. 2018;14(3):160-5. 